Artigo

\title{
Orientação Sexual na Escola: uma análise da sustentabilidade de políticas intersetoriais de Educação e Saúde no munícipio de São Paulo
}

\author{
Sexual Orientation at School: an analysis of the sustainability of intersectoral \\ education and health policies in the municipality of São Paulo
}

Orientación Sexual en la Escuela: un análisis de la sostenibilidad de las políticas de educación y salud intersectoriales en la cuidad de São Paulo

Renato Barbozaํㅡㄹ Lígia Rivero Pupo, ${ }^{2}$ Kátia Cibelle Machado Pirotta ${ }^{3}$.

\footnotetext{
${ }^{1}$ Filiação institucional. Cientista Social, Mestre em Saúde Coletiva (CCD/SES-SP), Pesquisador Científico V do Instituto de Saúde da Secretaria de Estado da Saúde de São Paulo e pesquisador do NEPAIDS da Universidade de São Paulo, São Paulo, SP, Brasil.

Correspondência: E-mail: renato@isaude.sp.gov.br

${ }^{2}$ Filiação institucional. Psicóloga, Mestre em Medicina Preventiva pela Universidade de São Paulo, Pesquisadora Científica IV do Instituto de Saúde da Secretaria de Estado da Saúde de São Paulo e pesquisadora do NEPAIDS da Universidade de São Paulo, São Paulo, SP, Brasil.

Correspondência: E-mail: ligia@isaude.sp.gov.br

3 Filiação institucional. Cientista Social, Mestre e Doutora em Saúde Pública pela Universidade São Paulo, Pesquisadora Científica V do Instituto de Saúde da Secretaria de Estado da Saúde de São Paulo, São Paulo, SP, Brasil.

Correspondência: $\quad$ E-mail: katia@isaude.sp.gov.br
}

Resumo Este artigo pretende contribuir para a discussão sobre a sustentabilidade de programas públicos, sobretudo na área da educação e da saúde. Objetiva-se compreender as dificuldades enfrentadas por três programas de orientação sexual na rede municipal de ensino de São Paulo, no período de 2001 a 2005, para garantir a continuidade e a sustentabilidade das ações. Foram realizadas entrevistas em profundidade com os atoreschave do processo e um estudo em fontes documentais. Observaram-se problemas de continuidade e de financiamento. As principais medidas para assegurar a sustentabilidade visavam inserir as ações na estrutura da instituição, garantir benefícios a professores capacitados e se respaldar na legislação. Os programas possuíam graus de influência 
variáveis e, consequentemente, maior ou menor facilidade em obter os meios para sua execução. A instituição apresentou pouca capacidade em realizar mudanças adaptativas, indicando falta de alinhamento com os programas. Não foi encontrada uma base social fortalecida de apoio aos programas.

Palavras-chaves: Sustentabilidade; Educação Sexual; Políticas Públicas.

Abstract This article aims to contribute to the discussion on public programs' sustainability, particularly in education and health. The objective is to understand the difficulties to ensure continuity and sustainability of actions for three sexual educational programs in the city of São Paulo in the period 2001-2005. It was conducted interviews in depth with key actors in the process and studied documentary sources. There were problems of continuity and funding. The main measures to ensure the sustainability aimed to insert the actions in the institution's structure, to assure benefits for the teachers' and to be supported by legislation. The programs had varying degrees of influence and, consequently, different degrees of facility in order to obtaining the means for its execution. The institution had little ability to make adaptive changes, indicating lack of alignment among the programs. It wasn't found a stronger social base for programs' support.

Keywords: Sustainability; Sex Education; Public Policies.

Resumen Este artículo tiene como objetivo contribuir a la discusión sobre la sostenibilidad de los programas públicos, especialmente en educación y salud. El objetivo es entender las dificultades que los tres programas de orientación sexual enfrentaram en la rede de ensino en la ciudad de São Paulo, en el periodo 2001 2005, para garantizar la continuidad y la sostenibilidad de las acciones. Se realizaron entrevistas a profundidad con actores claves del proceso y un estudio sobre las fuentes documentales. Fue observado problemas de continuidad y financiación. Las principales medidas para garantizar la sostenibilidad fueron la inserción de las acciones en la estructura de la institución, asegurando beneficios a maestros calificados y con respaldo legal. Los programas habían diversos grados de influencia y, portanto, mayor o menor facilidad en la obtención de los medios para su aplicación. La institución reveló poca capacidad de hacer cambios de adaptación, lo que indica la falta de coerencia con los programas. No fue observada uma base social fuerte y de apoyo a los programas.

Palabras Clave: Sostenibilidad; Educación Sexual; Políticas Públicas. 


\section{Introdução ${ }^{1}$}

A literatura científica sobre políticas e programas públicos na área da saúde e da educação possibilita identificar um número crescente de estudos e publicações dedicados à análise dos componentes envolvidos no processo de implementação de novos programas, projetos e intervenções. Esses estudos esquadrinham quais os fatores envolvidos na incorporação de novas tecnologias e avaliam os efeitos, a eficácia e a efetividade dos programas. (Hartz, 1997; Chaudoir et al., 2013; Bokhour et al., 2015; Gagliardi et al., 2015) Entretanto, mesmo com o acúmulo científico em torno destes temas, e embora exista um avanço significativo na habilidade de avaliar programas e intervenções, permanece uma preocupação crescente com a continuidade, a manutenção e resultados de longa duração, indicando a existência de lacunas do conhecimento e da análise relativa ao problema da sustentabilidade. (Stirman et al., 2012; Schell et al., 2013; Scheirer \& Dearing, 2011)

A continuidade das ações no campo das políticas públicas tem sido associada, na literatura, a variados termos, como institucionalização, manutenção, continuação, rotinização, durabilidade e sustentabilidade. (Fagen \& Flay, 2009; Scheirer \& Dearing, 2011; Stirman et al., 2012) Não obstante, o conceito de sustentabilidade é abordado como aquele que possui maior potência para explicar o dinamismo, a complexidade, a multidimensionalidade, a transitoriedade e os ajustamentos necessários à manutenção das políticas e dos programas implementados. (Fagen \& Flay, 2009)

O termo sustentabilidade foi proposto inicialmente, em 1987, pela Comissão Mundial sobre Meio Ambiente e Desenvolvimento, vinculada à Organização das Nações Unidas e passou a ser adotado pelos países membros nos debates sobre a questão do desenvolvimento econômico e social. (Comissão Mundial Sobre Meio Ambiente e Desenvolvimento, 1988) Nas décadas subsequentes, a crescente preocupação com a preservação do meio ambiente e o enfrentamento das desigualdades contribuiu para o avanço da definição do chamado "desenvolvimento sustentável", termo polissêmico e foco de disputas entre representantes de países desenvolvidos e os demais países, bem como entre ambientalistas e desenvolvimentistas. (Nascimento, 2012)

Em grande angular, o desenvolvimento sustentável busca suprir as necessidades do presente, sem comprometer a capacidade das gerações futuras em satisfazer suas próprias necessidades. (Comissão Mundial Sobre Meio Ambiente e Desenvolvimento, 1988; Lenzi, 2006). Nessa perspectiva, a busca da

\footnotetext{
${ }^{1}$ Agradecemos à Sylvia Cavasin e Sandra Unbehaum, pesquisadoras da Ecos-Comunicação em Sexualidade, que integraram a equipe de pesquisa responsável pelo projeto original.
} 
sustentabilidade passou a ser um dos principais desafios dos governos e da sociedade civil no processo de definição e implementação de políticas nacionais e internacionais, voltadas ao desenvolvimento econômico, ambiental e social, baseadas no princípio da equidade.

A revisão da literatura sobre a sustentabilidade revela que no campo teórico, o tema foi abordado inicialmente, como uma "ideia" ou "noção de sustentabilidade". Essa nomenclatura foi adotada pelas agências de cooperação internacional no final da década de 1980 e na década seguinte. Nesse cenário, a comunidade científica também avançou na discussão e na produção de evidências sobre esse tema emergente, contribuindo para a definição do conceito de sustentabilidade, atualmente utilizado por pesquisadores e gestores inseridos em diversos campos de produção de conhecimento, além das ciências que se dedicam ao estudo do meio ambiente. A noção de sustentabilidade foi adquirindo uma importância social e um acúmulo teórico que a elevou a categoria de conceito. Contudo, esse conceito mantém a sua polissemia e tem sido avaliado quanto à sua operacionalização, seja por instituições públicas ou privadas, em especial as que atuam no Terceiro Setor. (Nascimento, 2012; Oliveira et al., 2012)

Apesar de ser cada vez mais utilizado em diferentes áreas do conhecimento, o conceito de sustentabilidade concentra em seu interior duas ideias centrais que merecem uma clara distinção e compreensão. A primeira é a ideia de continuidade, permanência, manutenção e conservação. Nesse sentido, uma experiência é sustentável quando as diversas forças que se mobilizaram para concretizá-la em suas múltiplas dimensões continuam ativas, mesmo que modificadas, após o término do programa ou projeto.

Não é possível a existência de programas, ações e políticas sustentáveis, sem que as estruturas, os processos de trabalho, as ideias, as concepções e os recursos humanos, financeiros e técnicos sejam também sustentáveis. Logo, não se trata apenas da disponibilidade desses recursos, essenciais para a execução das políticas e das ações específicas decorrentes da sua implementação. Sustentar significa dar apoio, amparar, fornecer a base e o suporte fundamental para o reordenamento, a recomposição e o restabelecimento destes recursos imprescindíveis. A sustentação e a prioridade conferida a uma determinada política pública implica reconhece-la como uma estrutura legítima e relevante e também defende-la dos movimentos de fragmentação e desmobilização dos atores. A partir disso, são geradas as condições viáveis para a sua continuidade e permanência. Por esse motivo, aquilo que foi ou está sendo implantado, antes de ser modificado ou substituído merece sempre ser avaliado em sua adequação às necessidades do contexto social, em sua coerência e qualidade técnica e também quanto à sua eficácia e efetividade.

A segunda ideia refere-se à forma de atuação das instituições e dos atores quanto ao compromisso e a preocupação não apenas com o que se faz no presente, mas também com as consequências e as necessidades futuras. Assim, 
a incorporação do conceito de sustentabilidade na implantação e no desenvolvimento das políticas públicas implica mudanças na perspectiva dos atores, bem como das posturas e das atitudes adotadas no presente e sua repercussão no futuro. Portanto, requer a assunção de uma postura ética na condução do processo de implementação, sobretudo na análise dos efeitos das decisões tomadas em prol da coletividade beneficiária das ações. Desse modo, os elementos norteadores da sustentabilidade contemplam tanto a perspectiva de manter o que parece ser bom e adequado, como a perspectiva de criar estratégias e caminhos para reduzir a descontinuidade das propostas.

No campo das políticas e programas de saúde pública ou coletiva, pode-se dizer que "a sustentabilidade é o uso continuado dos componentes e atividades de um programa para a contínua realização de seus benefícios e resultados esperados." (Scheirer \& Dearing, 2011, p. 2060) Com o intento de incorporar a sustentabilidade em uma política ou programa, algumas questões precisam ser respondidas: o que é preciso reter para garantir a sustentabilidade? Quais são os fatores facilitadores da sustentabilidade e quais são suas principais barreiras? Em que momento deve-se pensar na sustentabilidade das ações de um projeto?

Recentes abordagens de sustentabilidade tem sugerido a importância da construção de um planejamento de sustentabilidade nos primeiros estágios de desenvolvimento de um programa. (Fagen \& Flay, 2015) A identificação prematura de problemas e adequação dos programas durante o seu processo de implementação evita a descontinuidade e a erosão das ações no decorrer do tempo. Ademais, a pesquisa em torno desse tema mostra que a probabilidade de sustentabilidade aumenta quando há um alinhamento entre: o reconhecimento do problema por parte de todos os atores envolvidos, o desenho do programa em questão, os objetivos e a capacidade da organização ou da comunidade que acolhe o projeto. (Scheirer \& Dearing, 2011)

De forma esquemática, com base em Scheirer e Dearing (2011), podemos classificar os principais fatores que influenciam na sustentabilidade de um programa em três grupos:

1) Características específicas da intervenção ou programa: se é flexível e adaptável, se é suportado por evidências, se tem credibilidade e benefícios conhecidos, se é fácil de ser aprendida, executada e mantida; e qual a capacidade de identificação dos componentes centrais e essenciais de tal intervenção/programa.

2) Características político-organizacionais e estruturais: ajuste entre a intervenção/programa e a missão e rotina organizacional; capacidade da organização em adaptar-se às mudanças; lideranças que apoiem a intervenção/programa; prioridades políticas; recursos existentes; recursos humanos capacitados para dar continuidade as ações; recursos financeiros estáveis; capacidade de monitorar as ações na medida em que estão sendo implantadas e fazer ajustes necessários. 
3) Características ambientais e contextuais: parceiros, rede social e comunitária de apoio; alianças e articulações locais; outros financiadores disponíveis; recursos humanos adicionais caso seja necessário.

No Brasil, a temática da sustentabilidade também está presente no campo da saúde coletiva justificada pela crescente interface entre a saúde e o meio ambiente e seus efeitos na multideterminação do processo saúde-doença. Nos últimos anos, a preocupação com a sustentabilidade em suas diferentes dimensões tem sido objeto de conferências realizadas pelas várias esferas da gestão pública e também tem contribuído na definição e implementação de programas estaduais e municipais. (Azevedo et al., 2012)

Nessa perspectiva, destaca-se a Política Nacional de Promoção da Saúde, editada pelo Ministério da Saúde em 2006 visando a promoção da qualidade de vida, a redução das vulnerabilidades e o enfrentamento dos determinantes sociais. (Brasil, 2006) Apesar dos esforços governamentais, os resultados ainda são pontuais, limitados e dependem da priorização e da capacidade programática dos estados e dos municípios na condução das agendas e dos planos de governo. Além disso, Akerman e colaboradores (2002) observam que é necessário engajar o maior número de participantes atuando em redes para se desenvolver a governança local, a exemplo do movimento "cidades/municípios saudáveis", estratégia de promoção da saúde em curso em algumas localidades do país.

Dentre suas diretrizes técnicas, a Política Nacional de Promoção da Saúde preconiza a necessidade de investimentos para o desenvolvimento de programas públicos baseados na intersetorialidade e na sustentabilidade. No que se refere à diretriz da intersetorialidade, o texto explicita o caráter fundamental da “articulação das possibilidades dos distintos setores de pensar a questão complexa da saúde, de corresponsabilizar-se pela garantia da saúde como direito humano e de cidadania, e de mobilizar-se na formulação de intervenções." (Brasil, 2006, p.13) Assim, a interface clássica, entre os setores da Saúde e da Educação no desenvolvimento de programas e projetos em parceria é primordial para a efetividade e o alcance dos resultados almejados.

As ações intersetoriais podem produzir resultados sinérgicos no desenvolvimento dos programas e dos projetos, contudo exigem uma nova racionalidade no processo da gestão das políticas públicas e na organização do processo de trabalho dos atores envolvidos, que desafia a produção de novos saberes e práticas, pois as instituições reproduzem uma lógica setorial, fragmentada e anacrônica. Essas ações implicam na:

articulação entre sujeitos de setores sociais diversos e, portanto, de saberes, poderes e vontades diversos, para enfrentar problemas complexos. É uma nova forma de trabalhar, de governar e de construir políticas públicas que pretende possibilitar a superação da fragmentação dos conhecimentos e das 
estruturas sociais para produzir efeitos mais significativos na saúde. (Feuerwerker \& Costa, 2000, p. 27)

A sexualidade, nas escolas, frequentemente foi tratada a partir de uma ótica moralizadora ou de disciplinarização dos corpos, com base nos saberes oriundos das práticas médicas e da biologia. (Altmann, 2001; Louro, 2004) Pouca atenção tem sido dada à orientação sexual sob o ponto de vista da autonomia, da construção de um projeto de vida, da equidade e do respeito à diversidade, presentes nos marcos norteadores dos Direitos Sexuais e Direitos Reprodutivos dos adolescentes, como na plataforma da Conferência de Beijing. (Organização das Nações Unidas, 1995) Não obstante, o governo brasileiro, através do Ministério da Saúde, tem reconhecido a importância de incentivar os adolescentes a adquirirem atitudes responsáveis e saudáveis a partir de temas estruturantes como a participação juvenil, a equidade de gênero, os Direitos Sexuais e Direitos Reprodutivos, à corresponsabilização dos atores e a intersetorialidade. (Brasil, 2010)

Visando contribuir com essa discussão, pretende-se com esse artigo analisar as características da sustentabilidade dos programas de orientação sexual implementados na rede municipal de ensino de São Paulo, entre os anos de 2001 a 2005. No período em estudo havia um cenário propício para a implantação de programas pautados por esses valores na Secretaria Municipal de Educação de São Paulo (SME-SP), configurando-se um momento privilegiado para a sua análise.

\section{Metodologia}

O presente estudo é um desdobramento do projeto de pesquisa “Educação Sexual na Escola e Direitos Sexuais e Reprodutivos - Avaliação da Política da Secretaria Municipal de Educação de São Paulo 2001 a 2005", desenvolvido em parceria pela Ecos - Comunicação em Sexualidade e Instituto de Saúde, financiado pelo Programa de Apoio a Projetos em Sexualidade e Saúde Reprodutiva - Prosare. (Pirotta et. al., 2006)

A pesquisa foi realizada na SME-SP, constituída por uma rede de 1.839 equipamentos, responsáveis pelo Ensino Infantil, Ensino Fundamental, Ensino de Educação de Jovens e Adultos e de Educação Especial. No período da pesquisa essa rede estava organizada em 13 Coordenadorias de Educação e posteriormente foi reorganizada administrativamente em 31 Subprefeituras.

Foi estudada a implantação e o desenvolvimento dos três principais projetos e programas relativos à orientação sexual no período de 2001 a 2005: o "Programa de Educação Preventiva e Sexualidade" (PEPS), desenvolvido entre 2001 e 2003, em parceria entre as Secretarias Municipais de Educação e da Saúde; o "Projeto Orientação Sexual na escola: um trabalho processual", uma parceria entre a Secretaria Municipal de Educação e uma Organização Não 
Governamental, no biênio 2003-2004; e o projeto “Vamos Combinar?", em parceria pelas Secretarias Municipais de Educação e da Saúde, iniciado em 2003 e estendendo-se até 2005.

Trata-se de um estudo qualitativo. Essa abordagem metodológica tem sido discutida por vários autores. Destaca-se a contribuição de Nogueira-Martins e Bógus que afirmam que:

\begin{abstract}
os métodos qualitativos produzem explicações contextuais para um pequeno número de casos, com uma ênfase no significado do fenômeno. O foco é centralizado no específico, no peculiar, almejando sempre a compreensão do fenômeno estudado, geralmente ligado a atitudes, crenças, motivações, sentimentos e pensamentos da população estudada. (Nogueira-Matins \& Bógus, 2004, p. 48)
\end{abstract}

Ao problematizar a importância das metodologias qualitativas, Minayo também aponta que:

são aquelas capazes de incorporar a questão do significado e da intencionalidade como inerentes aos atos, às relações e às estruturas sociais, sendo essas últimas tomadas tanto no seu advento quanto na sua transformação, como construções humanas significativas. (Minayo, 2004, p.10)

O presente projeto abordou a construção das políticas públicas no campo da orientação sexual e da saúde preventiva buscando conhecer os significados atribuídos pelos coordenadores e consultores que atuaram nos projetos e programas na SME-SP. Os métodos qualitativos permitem apreender as experiências e as práticas dos sujeitos que protagonizaram a condução das ações planejadas e vivenciaram as contradições e os entraves existentes no lócus institucional. Foram realizadas entrevistas em profundidade com três coordenadores e cinco consultores dos referidos projetos e programas, intencionalmente selecionados, devido a sua experiência acumulada nos temas abordados e na implementação de programas públicos no campo da educação em saúde. Além disso foram analisados documentos de gestão, relatórios e atos normativos referentes aos projetos e programas.

As entrevistas foram gravadas e transcritas. A técnica utilizada para analisá-las foi a análise de conteúdo, ancorada no referencial proposto por Bardin (1979), compreendendo as fases de pré-análise, exploração do material, tratamento dos resultados e interpretação. Segundo Bardin, a análise de conteúdo pode ser definida como:

um conjunto de técnicas de análise de comunicação visando obter, por procedimentos sistemáticos e objetivos de descrição do conteúdo das mensagens, indicadores (quantitativos ou não) que permitam a inferência de conhecimentos relativos às condições de produção/recepção destas mensagens. (Bardin, 1979, p.42) 
Inicialmente o material foi lido, sem a preocupação de categorizá-lo, mas tão somente para conhecermos seus sentidos e significados. Posteriormente, foram elaboradas categorias de análise, agrupando elementos, ideias, expressões e outros aspectos que apresentaram características comuns e que emergiram da leitura inicial, identificando as "unidades de registro" emergentes, bem como as "unidades de contexto" que circunscreveram o universo pesquisado.

Para a interpretação do material empírico obtido nas entrevistas, adotouse a categorização da sustentabilidade, organizada em três dimensões, as quais são absolutamente interdependentes e inter-relacionadas, ou seja: a sustentabilidade técnica, a política e a financeira. Trata-se apenas de uma divisão de ordem didática no intuito de aprofundar a compreensão dos fatores que condicionam e influenciam o processo de sustentabilidade de uma política ou programa.

No cenário das políticas públicas, a sustentabilidade técnica está associada à manutenção e ao aperfeiçoamento constante dos recursos humanos existentes; dos conceitos e concepções teórico-metodológicas; das estruturas, processos e recursos materiais necessários; das estratégias de monitoramento e avaliação das ações; do planejamento de médio e longo prazo. A sustentabilidade política está condicionada à priorização e à inserção dos programas e projetos no plano governamental; à articulação e à pactuação política entre os diferentes atores envolvidos; à criação de instrumentos e mecanismos de institucionalização das ações; à criação e manutenção dos espaços de gestão participativa e democrática para o controle social. A sustentabilidade financeira está relacionada à manutenção das fontes de recursos financeiros, na medida necessária para recompor e atualizar os valores investidos e garantir a expansão e a manutenção das ações, com vistas à sua efetividade ao longo do tempo.

Todos os entrevistados foram esclarecidos sobre os objetivos do estudo, sua importância e contribuição para as políticas públicas em orientação sexual. Após a leitura e assinatura do termo de consentimento livre e esclarecido, assegurando-se o direito à confidencialidade, anonimato e à privacidade dos entrevistados e com sua autorização prévia para a gravação dos depoimentos, foram iniciadas as entrevistas. O projeto foi aprovado pelo Comitê de Ética em Pesquisa do Instituto de Saúde da Secretaria de Estado da Saúde de São Paulo.

\section{Resultados e Discussão}

No período do estudo vários projetos e programas foram implantados na rede de ensino, cujos temas estavam relacionados à diversidade sexual, à construção da equidade e aos direitos humanos. Três deles se voltavam para o 
tema da orientação sexual e da educação preventiva e se destacaram pela magnitude e duração. Esses três programas foram implantados através de parcerias intersetoriais e da contratação de uma organização não governamental. Foram contratados consultores terceirizados para a realização de ações, os quais não pertenciam ao quadro da SME-SP. Os programas foram mantidos com recursos da SME-SP e de outras fontes financiadoras, seus desembolsos incluíram a aquisição de materiais pedagógicos e a remuneração dos consultores. Os programas se sucederam e, por vezes, foram realizados simultaneamente. Os temas e os enfoques variaram conforme o tipo de parceria e atores envolvidos. Embora tenham adotado diferentes medidas e estratégias de implantação, fortalecimento e sustentação, todos sofreram descontinuidades e enfrentaram diversos problemas ligados à sustentabilidade.

De forma geral, os três programas se preocuparam com a dimensão da sustentabilidade técnica investindo principalmente em estratégias de formação teórico-metodológica para os professores e outros atores da comunidade escolar. Desta maneira, ainda que com focos diferentes, e com níveis de aprofundamento distintos, eles se preocuparam em criar oportunidades e espaços para a reflexão e discussão das temáticas na busca da transformação de valores e atitudes. Para garantir a sustentabilidade nas escolas, os programas previam estratégias de suporte técnico tais como: elaboração, aquisição e distribuição de materiais didáticos (livros, vídeos, cartilhas, jogos, entre outros); supervisão e monitoramento das ações. O projeto Orientação Sexual realizou uma supervisão permanente de caráter teórico-operacional e os outros dois focaram o processo de supervisão apenas na verificação do cumprimento das ações.

Os encontros de supervisão não eram realizados no horário de trabalho dos professores, tendo obtido baixa adesão dos mesmos. Esse fato demonstrou a falta de mecanismos na estrutura SME-SP para a incorporação dessa atividade na rotina escolar e na agenda de trabalho das equipes dos projetos. A instituição revelou pouca capacidade de ajuste à realidade local, que, somada à contratação provisória e precária dos consultores, impossibilitou a manutenção da supervisão e do apoio técnico, após o término do projeto ou da gestão.

Este fato nos remete ao necessário ajuste entre as intervenções propostas, a realidade e o contexto institucional. Os estudos mostram que quanto maior a capacidade da instituição em fazer mudanças adaptativas, mais ela se compromete com a implementação e manutenção de um programa, sendo mais provável que tal inovação persista após o período de implantação do projeto. (Blasinsky et al., 2006) A sustentabilidade, nesse sentido, é vista como o produto de um alinhamento contínuo entre o programa e a organização que o implementa. (Scheirer \& Dearing, 2011)

No presente estudo, verificou-se a necessidade de um ajuste institucional para incorporar a atividade de supervisão, dado que esta é um dos pilares da sustentabilidade técnica das ações. Igualmente, outro aspecto que merece destaque é a importância do monitoramento de um programa. A capacidade de 
identificar precocemente os problemas relacionados à implantação de uma ação, fazendo os ajustes necessários para sua viabilização e não deixando esta tarefa a cargo dos atores da própria instituição é um elemento fundamental para a sustentabilidade. Essa capacidade possui uma dimensão ética. Autores como Scheirer e Dearing (2011) problematizam, se é ético propor um programa com intervenções inovadoras sem se responsabilizar pela sua continuidade, esperando que outros possam sustentá-las.

A ênfase dada pelos projetos à formação de funcionários concursados e não apenas àqueles que ocupam cargos de confiança na gestão da SME-SP não foi suficiente para a continuidade das ações. Depois da mudança de gestão e da interrupção ou término do projeto, esses técnicos, apesar de preparados e sensibilizados, ficaram sem o apoio da secretaria, de seus pares e dos profissionais que vieram a ocupar os cargos de confiança. Isolados e fragilizados, perderam a força política para continuarem as intervenções. Acabaram sendo atropelados por novas demandas e outras prioridades que the foram colocadas. “Na verdade a gente achou que as pessoas iam segurar sozinhas, e é irreal, ninguém segura sozinho." (entrevistado 4)

Outro obstáculo à sustentabilidade técnica está ligado ao fato de que tanto as ações de prevenção como as ações de orientação sexual tem impacto no plano simbólico e, portanto, precisam de um longo tempo de maturação para uma mudança de atitudes. Para ter um impacto real, essas ações precisam ser contínuas e devem sempre ser renovadas para dar conta das novas gerações que amadurecem sucessivamente para a vida sexual e reprodutiva. Logo, o tempo necessário para obter-se um impacto relevante nessa temática sempre será maior que o tempo da gestão e, por isso, dificilmente os resultados das ações poderão ser avaliados durante o período de sua implementação. Essa é uma atividade de caráter prospectivo e deveria fazer parte de um plano de governo, não restrita ao período de uma gestão.

Por tratar-se de questões que remetem ao plano cultural e que envolvem significados e valores instituídos, a sexualidade e as relações de gênero não podem ser compreendidas em apartado do jogo de forças políticas. As inflexões inerentes a esse processo expressam diferentes interesses materiais e ideológicos na arena política, cuja dinâmica favorece ou dificulta a (in)visibilidade e a continuidade desses temas na instituição escolar e na atenção à saúde sexual e reprodutiva dos adolescentes e jovens.

Outro problema identificado pelos coordenadores foi a aparente divergência de enfoque e de abordagem na temática da sexualidade entre os projetos, que reflete principalmente a diferença entre a tradição da educação e da saúde neste campo, bem como a divergência entre grupos que militam em temáticas específicas relacionadas à sexualidade, como grupos ligados às DST/AIDS, às drogas, à diversidade sexual, entre outros. 
Enquanto o projeto Orientação Sexual se preocupou em tratar a discussão da sexualidade a partir de um horizonte mais abrangente, abordando as dimensões psíquicas, culturais e biológicas, bem como o desenvolvimento sexual da infância até a adolescência, os outros dois projetos, realizados em parceria com a Secretaria Municipal de Saúde, preocuparam-se em focar suas ações na perspectiva da prevenção das DST/AIDS, gravidez indesejada e do abuso de drogas.

Os coordenadores apesar de considerarem legítimo, procedente e relevante o trabalho do outro, não concordavam entre si com a abordagem da sexualidade. Essa diferença de enfoque representou uma divergência ideológica e de interesses entre grupos com militâncias distintas, ainda que abordando elementos comuns.

Pra nós prevenção é uma coisa importante, mas você nunca pode entrar em sexualidade falando de prevenção, senão você já está falando de um problema (...). Então tem que falar do quê é, como o corpo funciona, e onde está essa sexualidade, então a gente achava preconceituoso, ultrapassado. Pra nós sexualidade é prazer. Aí todas as outras questões: a prevenção, a responsabilidade, o projeto de vida, tudo isso é consequência. (entrevistado 4)

Mesmo tendo trabalhado os mesmos temas e com estratégias de ação muito semelhantes, a falta de diálogo, de unicidade e de tentativa de composição entre os conceitos, as concepções e as metodologias resultou em uma fragmentação e territorialização dos projetos. Em nenhum momento os coordenadores e suas equipes discutiram essas diferenças teórico-conceituais de forma a construir alternativas para alcançar um alinhamento teórico e integrar as ações realizadas nas mesmas escolas.

A gente queria que os nossos dois grupos articulassem lá na ponta. Por exemplo, se tivesse um evento, tinha que ter o professor de OS [Projeto Orientação Sexual] e o professor do "Vamos Combinar". O consultor do OS não conhecia o do "Vamos Combinar" (...). Então no nível regional não existia essa articulação, mas acho que no central e no local também não. (entrevistado 4)

A institucionalização das ações é um aspecto da sustentabilidade técnica que envolve a criação de mecanismos e instrumentos de ordem política, técnica, financeira e jurídica que sustentem o desenvolvimento de ações na estrutura e na racionalidade das instituições. (Scheirer \& Dearing, 2011) Foram identificados três mecanismos para facilitar a incorporação das ações na SME-SP.

Um primeiro mecanismo instituído pelos três projetos foi a publicação em Diário Oficial (DO) tanto do teor de cada projeto, como de todas as ações desenvolvidas e dos profissionais capacitados nos cursos oferecidos: 
Diário Oficial é a bíblia, todo mundo lê o Diário Oficial, porque ali sai a tua evolução funcional. Então a gente publicava tudo no Diário Oficial" (entrevistado 2)

Então, era Diário Oficial, entendeu? Quando o cara completasse os três módulos ele tinha mais do que um ponto e meio, tinha dois pontos. Isso em termos de evolução era um salto de uma letra pra outra, então claro que todo mundo ia. (entrevistado 1)

Este mecanismo além de fornecer a visibilidade e a legitimidade para os projetos proporcionou benefícios concretos para os professores da rede, que tiveram a oportunidade de ascensão funcional com a participação nos cursos, o que implicou em aumento de salário e valorização profissional.

Um segundo mecanismo empregado para a institucionalização das ações foi o respaldo na Lei de Diretrizes e Bases da Educação (LDB) que instituiu a orientação sexual e a prevenção das DST/AIDS como temas transversais. Além disso, dois dos projetos analisados usaram um terceiro mecanismo para a inserção das ações nas escolas, qual seja, a inclusão dos planos de ação elaborados pelos professores e coordenadores pedagógicos nos Planos Políticos Pedagógicos (PPP). O principal produto do processo de capacitação era a elaboração de um projeto que viesse a ser implementado de forma interdisciplinar e com potencial de ser irradiado na comunidade escolar.

Ao analisar-se a dimensão da sustentabilidade política dos projetos, cinco fatores foram ressaltados: a inserção na estrutura da SME-SP; a capilarização das ações nas Coordenadorias de Ensino; as parcerias intersetoriais, em especial com a Secretaria Municipal da Saúde; a disputa política e a correlação de forças entre os atores internos e externos a SME-SP; e a base de sustentação social e comunitária.

A sustentabilidade das ações relaciona-se ao nível de apoio político e de liberdade de decisão concedido aos coordenadores e à equipe dos projetos, que, por sua vez depende da forma de inserção na estrutura da SME-SP. Apesar dos três projetos analisados receberem apoio político, as diferentes formas de inserção determinaram o seu grau de execução. O PEPS e o "Vamos Combinar" estavam submetidos ao Departamento de Orientação Técnica, responsável pela coordenação dos projetos na rede de ensino. Desse modo, estavam submetidos às decisões e níveis hierárquicos da secretaria, ao passo que o projeto Orientação Sexual estava ligado diretamente ao gabinete da secretaria de educação. Por esse motivo, conquistou maior espaço político e enfrentou menos burocracia, apresentando maior agilidade, facilidade na tomada de decisão e articulação na rede de ensino.

A interlocução com as coordenadorias regionais, ou seja, a capilarização das ações foi o segundo fator observado na análise da sustentabilidade política. 
Uma das estratégias encontradas foi a definição de um interlocutor permanente que respondesse pelo projeto e supervisão das escolas. Outra estratégia foi a sensibilização de profissionais da saúde e da educação, no nível regional. Além disso, um dos projetos buscou estabelecer uma referência de atenção à saúde para casos de DST/AIDS, violência sexual e para o acesso ao pré-natal e contraceptivos. Contudo, nos projetos com menor respaldo político no nível regional, as ações se tornaram muito mais custosas, enfrentando problemas logísticos e de infraestrutura, como a falta de salas e de equipamentos, atrasando o cronograma planejado. Isto revela o quanto é importante a preparação "do terreno" para o desenvolvimento das ações por parte de atores chave dos diferentes níveis da instituição.

O terceiro fator identificado foi a importância da intersetorialidade para a sustentabilidade política. Ela depende de uma definição precisa dos objetivos da parceria e da assunção dos papéis de cada setor envolvido, além da incorporação do projeto nas agendas de trabalho. Os projetos PEPS e "Vamos Combinar" foram implementados em parceria entre as Secretarias Municipais da Saúde e da Educação. Não obstante o reconhecimento da importância da articulação entre diferentes setores para a construção de um novo campo de saber e para a sustentabilidade de um programa, esse processo implica maior complexidade técnica e política, administração de conflitos de interesse e disponibilidade das fontes de financiamento. O projeto "Vamos Combinar" foi o que teve mais dificuldade para garantir a fluidez das ações intersetoriais, como observado por um dos informantes: "O profissional da Educação está de um lado e o da Saúde está de outro. Não existe uma relação direta. Isso é um trabalho que tem que ser construído gradativamente." (entrevistado 2)

A descontinuidade dos projetos associada à lógica da disputa política e à falta de compromisso dos gestores com o futuro das ações são os principais elementos relacionados ao quarto fator analisado na dimensão da sustentabilidade política. O que se constrói durante um período, frequentemente é desconstruído no período seguinte, como vocalizado neste depoimento:

As mudanças de gestão frequentemente provocam mudanças na estrutura da secretaria e principalmente de pessoal, o que sempre implica numa descontinuidade das ações. Tinha tudo pra continuar, porque já estava estruturado, mas aí mudou a Coordenadoria e a estrutura da própria Secretaria da Educação. A coordenadora que você demorou anos pra articular e sensibilizar, estabelecer uma relação de confiança, um vínculo, você não sabe nem pra onde foi. (entrevistado 2)

Observamos, no escopo do presente estudo, uma dinâmica na gestão pública que busca deixar uma marca própria que a diferencie da gestão anterior, muitas vezes desvalorizando e descartando ações já construídas sem a avaliação devida, o que torna inviável a nosso ver, a construção de uma lógica de continuidade. Constata-se que na execução das ações dos projetos investigados 
prevaleceu a temporalidade da gestão e não de uma política de Estado voltada para o enfrentamento de uma questão social relevante.

Nenhum projeto sequer conseguiu assegurar $o$ arquivamento $e$ a conservação dos documentos e materiais produzidos na SME-SP, incluindo os relatórios de avaliação da implementação das ações, os quais desapareceram. Esse fato reforça a importância de uma política de conservação documental, essencial para o estudo e a memória das experiências passadas.

Eu deixei cópias e cópias de tudo, e tudo com descrição, com a minha assinatura, memorando, e hoje meu memorando vale de quê? Eu tenho cópia de recibo e falaram na minha cara: "Olha, vocês não deixaram nada". "Como? Eu deixei". "Ah, não deixou nada". Sabe o quê eu aprendi? Que não se deve deixar nada; é minha triste lição, porque você vai ser acusada que não deixou. (entrevistado 4)

A noção de sustentabilidade envolve sempre um olhar em perspectiva, um norte e uma orientação para além do momento presente e do contexto político atual. Isso inclui uma preocupação com o bem público e o bem estar das gerações futuras e não apenas um compromisso com interesses de grupos específicos do presente. Dessa forma, a sustentabilidade depende do desenvolvimento de ações antecipadas que favoreçam a continuidade técnica, financeira e política dos projetos.

Um último fator da sustentabilidade política refere-se à base de sustentação social e comunitária, resultado de um reconhecimento social e político. Para isso é necessário haver articulação, envolvimento e pactuação política entre os diferentes atores sociais, aumentando a visibilidade e a legitimidade do tema em questão. Somente isso pode assegurar e salvaguardar a estabilidade dos programas e projetos. (Scheirer \& Dearing, 2011) Um coordenador entrevistado ressalta que "se você quer solidificar, você tem que ter base política, você tem que ter estrutura política, você tem que formar as pessoas, falar dos direitos." (entrevistado 1) Assim, constata-se que a responsabilidade por esse processo não deve ser restrita apenas a equipe do projeto, mas deve envolver os atores dos diferentes níveis das secretarias envolvidas, bem como os conselhos afins e outros grupos da sociedade civil. Fazse necessário a criação e o uso de espaços de gestão participativa e processos decisórios democráticos, que possibilitem o controle social.

Eu acho que a continuidade desses projetos depende muito do grau de autonomia dos educadores e da comunidade. Essa autonomia é muito pequena. Essa autonomia não pode ser outorgada, mas tem que ser conquistada, não é? Então, faltou isso. Quais são as escolas que têm um projeto de prevenção que está andando com as suas próprias pernas? Como é a articulação dessa escola com a sociedade civil? Falta uma rede que se crie de uma maneira mais independente. Eu acho que não tem outra saída. (entrevistado 5) 
A dimensão da sustentabilidade financeira relaciona-se à regularidade das fontes de recursos para o alcance dos objetivos ao longo do tempo. Verificou-se que a SME-SP financiou a maior parte dos projetos estudados. O PEPS foi financiado com recursos de convênio com o Ministério da Saúde através da Coordenação Nacional de DST/AIDS no valor original de R\$200 mil reais. Contudo, só foram aprovados $\mathrm{R} \$ 69$ mil reais, alocados no custeio das capacitações. Praticamente a totalidade do valor do projeto, cerca de $R \$ 2$ milhões de reais foram investidos pela própria Educação. O projeto Orientação Sexual foi custeado integralmente pela SME-SP no valor de R\$2 milhões de reais. O projeto "Vamos Combinar" recebeu recursos de três fontes: o Programa de DST/Aids da Secretaria Municipal de Saúde, o Programa Nacional de DST/AIDS e a SME-SP. Nos documentos analisados não foi possível identificar o valor alocado desse projeto.

Contudo, todos os projetos analisados tiveram problemas de descontinuidade no financiamento das ações durante o seu desenvolvimento. Nos projetos que envolviam múltiplas fontes de financiamento para o pagamento dos consultores houve atrasos relacionados ao processo administrativo exigido por cada fonte. Isso, segundo os coordenadores, em vários momentos fragilizou a execução das ações, que ficaram na dependência da "boa vontade" e do compromisso dos consultores. Mesmo o projeto Orientação Sexual, que não teve mais de uma fonte de financiamento, enfrentou dificuldades no segundo semestre de 2004, quando a SME-SP interrompeu o pagamento, retomando somente seis meses depois. A continuidade das ações dependeu novamente do compromisso, do interesse, e da militância dos consultores. A precarização dos vínculos na contratação dos consultores contribuiu para a descontinuidade das ações após o término da gestão. Nessa perspectiva, um consultor observou que "a gente não vai chegar a uma profundidade maior sem investir pra valer. É preciso investir dinheiro, acreditar e dar condições de trabalho." (entrevistado 8)

A afirmação acima chama a atenção para o caráter indissociável das três dimensões da sustentabilidade. Não obstante a relevância do investimento financeiro alocado pelas Secretarias para a realização dos projetos constata-se que esse elemento isoladamente não garante a sustentabilidade das ações. A competência técnica do quadro de profissionais envolvidos é também um fator fundamental para continuidade das atividades, contudo depende necessariamente da capacidade institucional de fixar esses recursos humanos oferecendo salários e condições de trabalho adequadas. Por sua vez, tratando-se do contexto da gestão pública, a dimensão política é essencial, pois o processo de decisão dos gestores garante a alocação eficaz dos elementos técnicos e financeiros necessários ao desenvolvimento dos projetos e programas.

Os estudos sobre sustentabilidade apoiam-se na premissa de que a mesma não é estável e requer adaptações permanentes e mudanças em relação ao que foi originalmente planejado. Nesse sentido, a sustentabilidade de um programa ou projeto nunca será total, mas sim parcial. No entanto, a literatura também aponta que a continuidade de um programa deve ser sustentada nos seus 
componentes centrais, ou seja, deve identificar quais são os elementos que precisam ser mantidos para que não haja a descaracterização dos objetivos e dos resultados esperados. (Scheirer \& Dearing, 2011) Um depoimento mostra que "faltou uma avaliação continuada e isso eu acho fundamental porque tudo fica a um nível, digamos, bem subjetivo: 'Esse projeto não funcionou'." (entrevistado 6)

No presente estudo, os relatos dos informantes evidenciaram que após 2005, com a transição da gestão municipal, todos os projetos foram descontinuados e o projeto da nova gestão, denominado "Escola Promotora da Saúde" rompeu com a concepção sustentadora adotada no campo da orientação sexual e dos direitos sexuais e reprodutivos, que alicerçaram o delineamento e a implementação dos projetos analisados. Um consultor entrevistado afirma que "no último ano caiu, porque era ano eleitoral e as coisas eram mais visíveis. A prioridade da nova gestão não era a educação sexual." (entrevistado 7)

O projeto adotado pela nova gestão da SME-SP baseou-se em princípios e modelos campanhistas do campo da saúde pública, adotando concepções biologizantes na abordagem da sexualidade nas escolas, o que é considerado um retrocesso segundo os referenciais teóricos críticos no campo da categoria gênero (Louro, 2004). Esse fato evidencia que não houve sustentabilidade parcial dos projetos da gestão anterior na medida em que sua concepção sustentadora foi irrompida.

\section{Considerações Finais}

Ao analisarmos os três projetos relacionados à orientação sexual, entre os anos de 2001 a 2005, podemos perceber que de forma geral, apesar de terem sido tomadas algumas medidas para garantir a sustentabilidade, elas não foram suficientes.

Em relação ao seu marco conceitual, os programas apresentaram concepções que estão em consonância com os princípios e as diretrizes contemporâneas voltadas à abordagem da sexualidade, reconhecendo os adolescentes como sujeitos de direitos, baseado no respeito a autonomia e equidade. Os três programas dirigiram esforços para a criação de espaços e oportunidades para a inserção da temática da sexualidade e da educação preventiva na comunidade escolar.

As medidas visando evitar a descontinuidade dos programas foram tomadas prioritariamente na dimensão técnica. Tais medidas visavam institucionalizar e aumentar a visibilidade das ações implementadas, através da utilização dos canais institucionais de comunicação, da inserção das capacitações como benefício à vida funcional dos professores e da apropriação das diretrizes sobre a sexualidade previstas na Lei de Diretrizes e Bases da Educação. No entanto, a rede de ensino apresentou pouca capacidade em realizar mudanças 
adaptativas, demonstrando falta de alinhamento com os programas, os quais não encontraram mecanismos facilitadores para a realização de ajustes durante o processo. Esse resultado indica que a dimensão técnica não foi suficiente para garantir a continuidade das ações.

Do ponto de vista da articulação entre os três programas, coexistiram linguagens e concepções diferentes. Essa situação reflete a territorialização dos temas, o que pode ter sido um fator de fragmentação. Nesse sentido, o grau de ajuste e de alinhamento interno aos programas foi pequeno, não produzindo adequações para a sua sustentabilidade.

A dimensão política revela-se como a mais complexa para a sustentabilidade. Os programas possuíam diferentes graus de influência na instituição e, consequentemente, maior ou menor facilidade para obter os meios para realizar as ações previstas. As estratégias para capilarizar as ações nem sempre conseguiram responder às necessidades, o que criou entraves para os programas. A intersetorialidade, por sua vez, implicou em uma maior complexidade técnica e política, prejudicando o andamento dos projetos nos quais essa característica era mais forte. A falta de compromisso com o futuro, atrelada a uma lógica política em que as ações executadas na gestão anterior são desvalorizadas pela atual, inviabilizou a permanência dos programas. Alia-se a esse quadro que não foi encontrada uma base social fortalecida que pudesse apoiar a sua continuidade. Os vários elementos presentes na dimensão política da sustentabilidade não dependiam diretamente da atuação dos coordenadores e sim dos dirigentes das Secretarias, detentores do poder e do processo decisório.

Do ponto de vista financeiro, a presença de várias fontes financiadoras, com diversos processos administrativos e burocráticos para os desembolsos, somada à contratação terceirizada de consultores, fragilizaram a execução das ações e levaram os programas a serem descontinuados, os quais só não foram cessados durante o seu desenvolvimento devido à um grupo de consultores que optou por manter as atividades voluntariamente.

A sustentabilidade financeira de um programa está diretamente associada à sua priorização e inserção como uma política de Estado, fortalecida e reconhecida socialmente. Nessa perspectiva, recomenda-se que na elaboração dos planos plurianuais das Secretarias Municipais de Educação e da Saúde seja definida uma rubrica específica para custear a implementação e a avaliação de programas e projetos voltados à orientação sexual, executados em caráter permanente.

Neste estudo foi possível verificar que as iniciativas estavam relacionadas à trajetória pessoal e política dos atores - idealizadores, gestores, ou coordenadores - no espaço público. Assim, foi possível observar o quanto os programas analisados apresentaram experiências "personalizadas". Não se trata, é óbvio, de desconsiderar aquilo que os sujeitos podem agregar a uma ação técnica e política, mas sim de dimensionar os programas frente à necessidade de 
garantir sua pauta programática e sua sustentabilidade para além das performances dos gestores.

Recomenda-se que os programas que operacionalizam as políticas públicas devem apresentar condições de serem monitorados e avaliados para sua continuidade, bem como devem ser submetidos à fiscalização e acompanhamento das instâncias responsáveis pelo controle social, instrumento democrático conquistado pela sociedade civil, que necessita ser aperfeiçoado e incorporado ao cotidiano da gestão pública.

Dentre os caminhos possíveis para a gestão das políticas públicas, não se pode olvidar da relevância que o protagonismo dos atores da comunidade escolar, especialmente dos alunos, adquire. A participação ativa da comunidade escolar é fundamental para avançar no campo da orientação sexual, a partir de concepções sustentadoras ancoradas na perspectiva da transversalidade, abordando a sexualidade nos projetos de vida, com o respeito à equidade de gêneros, à não discriminação e para a construção de uma cultura de paz.

\section{Referências Bibliográficas}

Akerman, Marco., Mendes, Rosilda., Bógus, Cláudia M., Westphal, Márcia F., Bichir, Aluisio Bichir \& Pedroso, Mylene L. (2002). Avaliação em promoção da saúde: foco no "município saudável". Revista de Saúde Pública, 36(5), 63846.

Altmann, Helena. (2001). Orientação sexual nos Parâmetros Curriculares Nacionais. Revista Estudos Feministas, 9(2), 575-585.

Azevedo, Elaine., Pelicioni, Maria C.F., \& Westphal, Marcia F. (2012). Práticas intersetoriais nas políticas públicas de promoção de saúde. Physis Revista de Saúde Coletiva, 22(4), 1333-1356.

Bardin, Laurence. (1979). Análise de conteúdo. Lisboa: Edições 70.

Blasinsky, Margaret., Goldman, Howard H., \& Unützer, Jürgen. (2006). Project IMPACT: a report on barriers and facilitators to sustainability. Administration and Policy in Mental Health and Mental Health Services Research, 33(6), 718729.

Bokhour, Barbara G., Saifu, Hemen., Goetz, Matthew B., Fix, Gemmae M., Burgess, Jane., Fletcher, Michael D., Knapp, Herschel., \& Asch, Steven M. (2015). The role of evidence and context for implementing a multimodal intervention to increase HIV testing. Implementation Science, 10(22), 1-12. 
Brasil. (2006). Política Nacional de Promoção da Saúde. Brasillia: Ministério da Saúde. Disponível na internet em: http://bvsms.saude.gov.br/bvs/publicacoes/politica_nacional_promocao_saude _3ed.pdf. [ Data de acesso: 10 dez. 2014].

Brasil. (2010). Diretrizes nacionais para a atenção integral à saúde de adolescentes e jovens a promoção, proteção e recuperação da saúde. Brasília: Ministério da Saúde. Disponível na internet em: http://bvsms.saude.gov.br/bvs/publicacoes/diretrizes_nacionais_atencao_saud e_adolescentes_ovens_promocao_saude.pdf [ Data de acesso: 11 fev. 2016].

Chaudoir, Stephenie R., Dugan, Alicia G., \& Barr, Colin H. (2013). Measuring factors affecting implementation of health innovations: a systematic review of structural, organizational, provider, patient, and innovation level measures. Implementation Science, 8(22), 1-20.

Comissão Mundial Sobre Meio Ambiente e Desenvolvimento - CMMAD. (1988). Nosso futuro comum. Rio de Janeiro: Fundação Getúlio Vargas.

Fagen, Michael C., \& Flay, Brian R. (2009). Sustaining a school-based prevention program: Results from the Aban Aya sustainability project. Health Education \& Behavior, 36(1), 9-23.

Feuerwerker, Laura C. M. \& Costa, Heloniza O. G. (2000). Intersetorialidade na rede Unida. Saúde em Debate, 22, 25-35.

Gagliardi, Anna R., Marshall, Catherine., Huckson, Sue., James, Roberta., \& Moore, Val. (2015). Developing a checklist for guideline implementation planning: review and synthesis of guideline development and implementation advice. Implementation Science, 10(19), 1-9.

Hartz, Zulmira M. A. (1997). Avaliação em Saúde: dos modelos conceituais à prática na análise da implantação de programas. Rio de Janeiro: Fiocruz.

Lenzi, Cristiano L. (2006). Sociologia Ambiental: risco e sustentabilidade na modernidade. São Paulo: Bauru: Anpocs/Edusc.

Louro, Guacira L. (2004). Gênero, sexualidade e educação. Petrópolis: Vozes.

Minayo, Maria C. S. (2004). O desafio do conhecimento: pesquisa qualitativa em saúde. São Paulo, Rio de Janeiro: Hucitec/Abrasco.

Nascimento, Elimar P. (2012). Trajetória da sustentabilidade: do ambiental ao social, do social ao econômico. Estudos Avançados, 26(74), 51-64.

Nogueira-Martins, Maria Cezira F. \& Bógus, Claudia M. (2004). Considerações sobre a metodologia qualitativa como recurso para o estudo das ações de humanização em saúde. Saúde e Sociedade, 13(3), 44-57. 
Oliveira, Lucas R., Medeiros, Raffaela M., Terra, Pedro de B., \& Quelhas, Osvaldo L.G. (2012). Sustentabilidade: da evolução dos conceitos à implementação como estratégia nas organizações. Produção, 22(1), 70-82. Disponível na internet em: http://www.scielo.br/scielo.php?script=sci_arttext\&pid=\$010365132012000100006\&lng=pt\&nrm=iso. [ Data de acesso: 12 fev. 2015].

Organização das Nações Unidas. The Fourth World Conference on Women Beijing Declaration and Platform for Action. 1995. Disponível na internet em: http://www.un.org/womenwatch/daw/beijing/pdf/BDPfA\%20E.pdf [ Data de acesso: 11 fev. 2016].

Pirotta, Katia C. M., Pupo, Lígia R., Barboza, Renato., Unbehaum, Sandra., \& Cavasin, Sylvia. (2006). Educação Sexual na Escola e Direitos Sexuais e Reprodutivos - Avaliação da Política da Secretaria Municipal de Educação de São Paulo 2001 a 2005. Relatório final de pesquisa. Ecos Comunicação em Sexualidade/Instituto de Saúde.

Scheirer, Mary A., \& Dearing, James W. (2011). An Agenda for Research on the Sustainability of Public Health Programs. American Journal of Public Health, 101(11), 2059-2067.

Schell, Sarah F., Luke, Douglas A., Schooley, Michael W., Elliott, Michael B., Herbers, Stephanie H., Mueller, Nancy B., \& Bunger, Alicia C. (2013). Public health program capacity for sustainability: a new framework. Implementation Science, 8(15), 10-10.

Stirman, Shannon W., Kimberly, John., Cook, Natasha., Calloway, Amber., Castro, Frank \& Charns, Martin. (2012). The sustainability of new programs and innovations: a review of the empirical literature and recommendations for future research. Implementation Science, 7(17), 1-16. 